\title{
Desempenho e características de carcaça de cordeiros alimentados com dietas contendo alta proporção de concentrado adicionadas de agentes tamponantes ${ }^{1}$
}

\section{Adilson Luis Gastaldello Junior ${ }^{2}$, Alexandre Vaz Pires ${ }^{3}$, Ivanete Susin ${ }^{3}$, Clayton Quirino Mendes $^{2}$, Evandro Maia Ferreira ${ }^{2}$, Gerson Barreto Mourão ${ }^{3}$}

${ }^{1}$ Projeto financiado pela FAPESP

2 Progama de pós-graduação em Ciência Animal e Pastagens - ESALQ/USP - Piracicaba, SP.

${ }^{3}$ Departamento de Zootecnia - ESALQ/USP - Piracicaba, SP.

RESUMO - Objetivou-se com este estudo avaliar os efeitos da adição de bicarbonato de sódio ou de fontes de calcário com diferentes granulometrias na ração, associadas ou não a monensina sódica, sobre o desempenho e as características de carcaça de cordeiros confinados recebendo dietas contendo alta proporção de concentrado. Quarenta e dois cordeiros Santa Inês com peso inicial de $21 \pm 3 \mathrm{~kg}$ e $88 \pm 5$ dias de idade foram distribuídos em blocos completos casualizados em arranjo fatorial $2 \times 3$, com seis tratamentos e sete repetições. Os animais foram alimentados com rações contendo $90 \%$ de concentrado, $10 \%$ de feno de “coastcross”, uma fonte de calcário (calcário calcítico ou calcário calcítico tipo filler) ou bicarbonato de sódio $\left(\mathrm{NaHCO}_{3}\right)$, com ou sem adição de monensina sódica (30 mg/kg da MS). Não foi observada influência dos agentes tamponantes no consumo de matéria seca e no ganho de peso médio diário. Entretanto, a conversão alimentar dos animais alimentados com as rações contendo monensina sódica (3,32 kg MS/kg de ganho) foi melhor que naqueles que consumiram as rações sem esse aditivo (3,58 $\mathrm{kg} \mathrm{MS} / \mathrm{kg}$ de ganho). Não houve efeito dos agentes tamponantes nos parâmetros de carcaça avaliados, observando-se valores médios de 50,4\%; 2,4\%; 13,9 cm² e 1,9 mm para o rendimento de carcaça quente, a perda por resfriamento, a área de olho-de-lombo e a espessura de gordura, respectivamente. A adição de monensina melhora a conversão alimentar e pode aumentar a rentabilidade do sistema de produção de cordeiros confinados.

Palavras-chave: fontes de calcário, ionóforos, monensina sódica, pH, rúmen, terminação

\section{Performance and carcass characteristics of feedlot lambs fed high grain diets with buffer compounds}

ABSTRACT - The objective of this study was to assess the effects of adding sodium bicarbonate or limestone sources with different particle sizes to the diet, and their interaction with sodium monensin, on the performance and carcass characteristics of feedlot lambs fed fed high grain diets. Forty two Santa Ines lambs were used with $21 \pm 3 \mathrm{~kg}$ initial average body weight and $88 \pm 5$ days old in feedlot, placed a randomized complete block design in a $2 \times 3$ factorial arrangement with six treatments and seven replications. Animals were fed diet containing $90 \%$ concentrate, $10 \%$ "coastcross" hay, with one source of limestone (limestone or "filler" limestone) or sodium bicarbonate $\left(\mathrm{NaHCO}_{3}\right)$, with or without monensin (30 mg/kg DM). No influence was observed of the buffering agents on dry matter intake or average daily gain. However, the feed conversion of the animals fed diet containing sodium monensin (3.34 $\mathrm{kg} \mathrm{DM} / \mathrm{kg}$ gain) was better than those fed diets containing monensin (3.32 kg DM/ $/ \mathrm{kg}$ gain) compared to diets without monensin ( $3.58 \mathrm{~kg} \mathrm{DM} / \mathrm{kg}$ gain). There was no effect of the buffering agents on the carcass characteristics assessed: the mean values were $50.4 \%, 2.42 \%, 13.9 \mathrm{~cm}^{2}$ and $1.9 \mathrm{~mm}$ hot carcass weight, chilling losses, longissimus muscle area and fat thickness, respectively. Adding monensin to the diet improves feed conversion and may make the feedlot lambs system more profitable.

Key Words: ionophores, finishing, limestone sources, monensin, $\mathrm{pH}$, rumen

\section{Introdução}

O confinamento é uma alternativa interessante para a terminação de cordeiros em comparação à utilização de pastagens. De acordo com Susin \& Mendes (2007), cordeiros confinados apresentam ganho de peso mais acelerado, resultando em maior rendimento de carcaça e carne de melhor qualidade. Em confinamento, a dieta de custo mínimo é, na maioria das vezes, aquela com alta proporção de concentrado (Susin, 2003). Dietas com essas

Recebido em 28/11/2007 e aprovado em 20/3/2009.

Correspondências devem ser enviadas para: alvpires@esalq.usp.br 
características apresentam concentrações elevadas de carboidratos não fibrosos, os quais são rapidamente fermentados no rúmen e possuem baixa quantidade de fibra proveniente da forragem, o que pode reduzir o $\mathrm{pH}$ ruminal e a digestão de fibra, prejudicando o desempenho animal. De acordo com Santra et al. (2002), a utilização de substâncias tamponantes em rações com alta proporção de concentrado pode ajudar a manter o $\mathrm{pH}$ ruminal constante, favorecendo o crescimento microbiano e melhorando a digestão da fibra e o desempenho do animal.

Além dos tamponantes, existe no mercado um grupo de antibióticos promotores de crescimento conhecidos como ionóforos, dentre os quais a monensina sódica destaca-se como o mais estudado, principalmente na alimentação de bovinos (Goodrich et al., 1984). A adição de ionóforos em dietas com alta proporção de concentrado para ruminantes pode diminuir a perda energética na forma de metano e melhorar a conversão alimentar. Essa estratégia tem sido uma alternativa para reduzir os custos de produção, além de proporcionar maior saúde, bem-estar animal e contribuir para reduzir o impacto ambiental da atividade pecuária (Bergen \& Bates, 1984).

Objetivou-se com este estudo avaliar os efeitos da adição de bicarbonato de sódio ou fontes de calcário com diferentes granulometrias, associadas ou não a monensina sódica, sobre o desempenho e as características de carcaça de cordeiros confinados recebendo rações com alta proporção de concentrado.

\section{Material e Métodos}

O experimento foi realizado no Sistema Intensivo de Produção de Ovinos e Caprinos do Departamento de Zootecnia da Escola Superior de Agricultura "Luiz de Queiroz”(ESALQ), Piracicaba, SP.

Foram utilizados 42 cordeiros Santa Inês, nãocastrados, com peso médio inicial de $21 \pm 3 \mathrm{~kg}$ e idade média inicial de $88 \pm 5$ dias. Os animais foram confinados em baias cobertas, com piso de concreto e livre acesso ao cocho e ao bebedouro, sendo um animal por baia e sete baias por tratamento.

Todos os animais foram everminados e vacinados contra clostridioses e receberam aplicação de suplemento vitamínico ADE antes do início do experimento. No início e ao longo do experimento, avaliou-se a ocorrência de coccidioses e verminoses por exame de contagem de ovos por grama de fezes para controle dessas enfermidades.

O período experimental teve duração de 56 dias, divididos em dois subperíodos de 28 dias. As pesagens dos animais foram realizadas nos dias 0,28 e 56 do período experimental, após jejum alimentar de 14 horas. As rações experimentais (Tabela 1) foram formuladas para serem isonitrogenadas (18\% PB) e continham $10 \%$ de feno de “coastcross" picado e 90\% de concentrado na matéria seca, diferindo quanto às fontes de calcário, à adição de bicarbonato de sódio e à presença ou ausência de monensina sódica. Os tratamentos foram: calcário calcítico (1,3\%); calcário calcítico tipo filler (1,3\%); calcário calcítico (1,3\%) + bicarbonato de sódio,

Tabela 1 - Composição nutricional das dietas experimentais (\%MS)

\begin{tabular}{|c|c|c|c|c|c|c|}
\hline \multirow[b]{3}{*}{ Item } & \multicolumn{6}{|c|}{ Dieta } \\
\hline & \multicolumn{3}{|c|}{ Com monensina } & \multicolumn{3}{|c|}{ Sem monensina } \\
\hline & $\begin{array}{l}\text { Calcário } \\
\text { calcítico }\end{array}$ & $\begin{array}{c}\text { Calcário calcítico } \\
\text { tipo filler }\end{array}$ & $\begin{array}{l}\text { Calcário calcítico + } \\
\text { bicarbonato de sódio }\end{array}$ & $\begin{array}{l}\text { Calcário } \\
\text { calcítico }\end{array}$ & $\begin{array}{c}\text { Calcário calcítico } \\
\text { tipo filler }\end{array}$ & $\begin{array}{l}\text { Calcário calcítico + } \\
\text { bicarbonato de sódio }\end{array}$ \\
\hline \multicolumn{7}{|l|}{ Ingredientes } \\
\hline Milho moído grosso & 70,8 & 70,8 & 69,5 & 70,8 & 70,8 & 69,5 \\
\hline Farelo de soja & 15,9 & 15,9 & 16,2 & 15,9 & 15,9 & 16,2 \\
\hline Sal mineral ${ }^{1}$ & 1,5 & 1,5 & 1,5 & 1,5 & 1,5 & 1,5 \\
\hline Cloreto de amônia & 0,5 & 0,5 & 0,5 & 0,5 & 0,5 & 0,5 \\
\hline Calcário calcítico & 1,3 & - & 1,3 & 1,3 & - & 1,3 \\
\hline Calcário calcítico (filler) & - & 1,3 & - & - & 1,3 & - \\
\hline Monensina sódica & 0,03 & 0,03 & 0,03 & - & - & - \\
\hline Bicarbonato de sódio & - & - & 1,0 & - & - & 1,0 \\
\hline Feno “coastcross” & 10,0 & 10,0 & 10,0 & 10,0 & 10,0 & 10,0 \\
\hline \multicolumn{7}{|l|}{ Composição nutricional } \\
\hline Matéria seca & 89,5 & 89,7 & 89,6 & 89,8 & 89,9 & 89,7 \\
\hline Matéria mineral, \% MS & 4,7 & 5,6 & 5,6 & 5,3 & 5,5 & 5,5 \\
\hline Proteína bruta, \% MS & 18,7 & 17,3 & 18,7 & 18,9 & 18,3 & 18,4 \\
\hline Fibra em detergente neutro, \% MS & 23,7 & 22,4 & 22,1 & 22,0 & 21,9 & 22,7 \\
\hline
\end{tabular}

${ }^{1}$ Composição: P - 7,5\%; Ca - 19\%; Mg - 1\%; S - 7\%; Na - 14,3\%; Cl - 21,8\%; Fe - 500 ppm; Cu - 300 ppm; Zn - 4.600 ppm; Mn - 1.100 ppm; I - 80 ppm; Co - 405 ppm; Se - 30 ppm. 
$\mathrm{NaHCO}_{3}(1 \%)$, com e sem monensina sódica (30 mg/kg da MS).

As rações foram formuladas de forma a atenderem às exigências dos animas segundo o NRC (2007). Para a monensina sódica, utilizou-se a dosagem recomendada pelo fabricante. A quantidade de bicarbonato de sódio utilizada foi definida conforme os dados reportados na literatura, considerando controle a ração com calcário calcítico comum contendo monensina sódica, por ser a ração padrão utilizada em muitos sistemas de produção de cordeiros em confinamento.

O milho foi processado em desintegrador sem peneira, caracterizando moagem grosseira do ingrediente. $\mathrm{O}$ feno foi picado no mesmo equipamento, porém com peneira de crivos de $1 \mathrm{~cm}$, para garantir homogeneização desse ingrediente na ração e evitar seleção pelos animais. Todos os ingredientes, previamente pesados, foram homogeneizados em misturador horizontal com capacidade para $500 \mathrm{~kg}$.

As rações foram pesadas e ofertadas à vontade duas vezes por semana. As sobras de ração de cada baia foram pesadas semanalmente para determinação do consumo diário de MS por animal e retornadas ao cocho. Amostras de cada partida da ração ofertada foram colhidas e conservadas a $-18^{\circ} \mathrm{C}$.

Posteriormente, foram descongeladas, compostas por tratamento e por período e analisadas para determinação da matéria seca, segundo procedimento descrito por Goering \& Van Soest (1970), da matéria mineral e da proteína bruta, de acordo com AOAC (1990). A fibra em detergente neutro (FDN) foi determinada utilizando-se amilase e sulfito de sódio, conforme descrito por Van Soest et al. (1991). A matéria orgânica foi calculada pela diferença entre a matéria seca e a matéria mineral.

Ao final do período experimental, os animais apresentavam peso corporal médio de $37 \mathrm{~kg}$, porém, para avaliação dos parâmetros de carcaça, foram mantidos em confinamento em média por mais 10 dias, recebendo as rações experimentais até atingirem o peso corporal de abate (40 kg). O abate foi realizado após jejum alimentar de 14 horas.

Após o abate, a esfola e a retirada das vísceras, os cordeiros foram pesados para obtenção do peso de carcaça quente e as carcaças foram mantidas em câmara de refrigeração a $4{ }^{\circ} \mathrm{C}$ por 24 horas. Após esse período, as carcaças foram novamente pesadas para obtenção do peso de carcaça fria. Para determinação do rendimento de carcaça quente (RCQ), do rendimento de carcaça fria (RCF) e da perda por resfriamento (PR), foram utilizadas as fórmulas que seguem: $\mathrm{RCQ}=(\mathrm{PCQ} / \mathrm{PCA}) \times 100 ; \mathrm{RCF}=(\mathrm{PCF} / \mathrm{PCA}) \mathrm{x}$ $100 ; \mathrm{PR}=[(\mathrm{PCQ}-\mathrm{PCF}) / \mathrm{PCQ}] \times 100$.
A medida da espessura de gordura (EG) foi tomada entre a $12^{\underline{a}}$ e a $13^{\underline{a}}$ costela na parte anterior da meia-carcaça, utilizando-se paquímetro graduado em milímetros. A área de olho-de-lombo (AOL) foi desenhada em papel-vegetal, delimitando o contorno do músculo exposto longissimus dorsi, e posteriormente mensurada pelo sistema Plastic Grid, graduado em milímetros.

O delineamento utilizado foi o de blocos completos casualizados, com seis tratamentos e sete repetições, em fatorial $2 \times 3$, composto de dois níveis de monensina sódica (0 e $30 \mathrm{mg} / \mathrm{kg}$ MS) e da adição dos tamponantes calcário calcítico, calcário calcítico filler ou bicarbonato de sódio. Os blocos foram definidos de acordo com o peso e a idade dos animais no início do experimento. Os resultados foram submetidos à análise de variância utilizando-se o procedimento GLM do SAS (1999), que separou como causa de variação o efeito dos tamponantes, o efeito da monensina e o efeito da interação entre tamponantes e monensina, considerando o nível de significância de 5\%.

\section{Resultados e Discussão}

Não houve interação $(P>0,05)$ entre a monensina e os tamponantes. Com isso, os efeitos da adição de monensina e tamponantes foram analisados agrupadamente.

Para as variáveis ganho médio diário de peso (GMD), consumo de matéria seca (CMS) em kg/dia, g/kg PC 0,75 e \% PC, não houve efeito $(\mathrm{P}>0,05)$ da adição de monensina sódica (Tabela 2) nem da adição dos tamponantes (Tabela 3). Entretanto, verificou-se melhora $(\mathrm{P}<0,05)$ na conversão alimentar com a inclusão de monensina sódica,mas não houve efeito $(\mathrm{P}>0,05)$ dos tamponantes.

A ausência de efeito da monensina sódica sobre o consumo de MS contraria a hipótese relatada por Schelling (1984) de que os ionóforos reduzem o consumo voluntário de rações com alta proporção de concentrado. Entretanto, de acordo com esse autor, em sistemas de confinamento de bovinos com alta proporção de concentrado, a média é de $10,7 \%$ de redução no consumo quando se fornece monensina na ração, mas cerca de $16 \%$ da redução do consumo ocorre no início do experimento quando há mudança na ração e a adição de monensina. Além disso, após 112 dias aproximadamente, essa redução no consumo cai para $5 \%$, indicando que pode estar relacionada principalmente à adaptação dos animais e menos aos efeitos quimiostáticos do melhor aproveitamento energético da ração. Possivelmente, os cordeiros deste estudo não apresentaram redução significativa no consumo por estarem adaptados ao consumo de rações com alto teor de 
concentrado. Contudo, apesar do efeito não-significativo sobre o consumo de MS, foi observada influência na conversão alimentar, o que indica melhor aproveitamento da ração pelos animais. Os resultados obtidos neste experimento estão de acordo com os verificados por Mendes et al. (2000), que avaliaram o desempenho de cordeiros alimentados com rações contendo alta proporção de concentrado e $28 \mathrm{mg} / \mathrm{kg}$ de MS de monensina sódica, e não verificaram efeito no desempenho dos animais.

De acordo com Bergen \& Bates (1984), em rações com alta proporção de concentrado, a adição de monensina sódica reduz o consumo de MS, mas não afeta o ganho médio diário dos animais e ainda melhora a conversão alimentar. Goodrich et al. (1984) compilaram dados de 228 experimentos e observaram melhora de 7,5\% na conversão alimentar. Da mesma forma, neste trabalho, a adição de monensina sódica melhorou a conversão alimentar em 7,3\%, o que pode ser explicado pela melhora na eficiência do metabolismo energético, atribuída ao aumento da concentração de propionato e à redução nas concentrações de acetato e butirato, além da redução nas perdas energéticas na forma de metano (Bergen \& Bates, 1984; Bagg, 1997). A inclusão de monensina sódica na ração também pode aumentar a eficiência de uso da amônia ruminal $\left(\mathrm{N}-\mathrm{NH}_{3}\right)$ por possibilitar maior aporte energético para crescimento microbiano, o que proporciona melhor aproveitamento da proteína da dieta e redução das perdas na forma de amônia. Além disso, pode ocorrer menor deaminação no ambiente ruminal, em virtude da ação da monensina sobre grupos de bactérias gram-positivas e de protozoários que degradam proteína e produzem amônia aumentando a taxa de proteína não-degradável no rúmen (Russell \& Strobel, 1989).

Tabela 2 - Desempenho de cordeiros alimentados com dietas contendo alta proporção de concentrado em associação à monensina sódica

\begin{tabular}{|c|c|c|c|c|}
\hline \multirow[b]{2}{*}{ Item } & \multicolumn{2}{|c|}{ Dieta } & \multirow[b]{2}{*}{$\mathrm{EPM}^{2}$} & \multirow[b]{2}{*}{$\mathrm{P}^{3}$} \\
\hline & Com monensina & Sem monensina & & \\
\hline Número de animais & 21 & 21 & & \\
\hline Idade inicial, dias & 87,6 & 88,0 & & \\
\hline Idade final, dias & 143,0 & 143,6 & & \\
\hline Peso inicial, kg & 21,1 & 21,4 & & \\
\hline Peso final, kg & 37,6 & 37,4 & 0,16 & NS \\
\hline Ganho médio diário, kg & 0,29 & 0,28 & 0,006 & NS \\
\hline \multicolumn{5}{|l|}{ Consumo de matéria seca } \\
\hline $\mathrm{kg} / \mathrm{dia}$ & 0,970 & 1,019 & 0,001 & NS \\
\hline g/kg (peso $\left.{ }^{0,75}\right)$ & 76,94 & 80,25 & 0,17 & NS \\
\hline$\%$ Peso & 3,30 & 3,43 & 0,04 & NS \\
\hline Conversão alimentar, kg MS/kg ganho & $3,32 \mathrm{a}$ & $3,58 b$ & 0,07 & 0,0443 \\
\hline
\end{tabular}

${ }^{1}$ Médias obtidas com ou sem adição de monensina.

2 Erro-padrão da média.

${ }^{3}$ Probabilidade de efeito dos tratamentos.

a,b Médias seguidas de letras distintas na mesma linha diferem pelo teste Tukey.

Tabela 3 - Desempenho de cordeiros alimentados com dietas contendo alta proporção de concentrado em associação a agentes tamponantes

\begin{tabular}{|c|c|c|c|c|c|}
\hline \multirow[b]{2}{*}{ Item } & \multicolumn{3}{|c|}{ Agente tamponante } & \multirow[b]{2}{*}{$\mathrm{EPM}^{1}$} & \multirow[b]{2}{*}{$\mathrm{P}^{2}$} \\
\hline & $\begin{array}{l}\text { Calcário } \\
\text { calcítico }\end{array}$ & $\begin{array}{c}\text { Calcário calcítico } \\
\text { tipo filler }\end{array}$ & $\begin{array}{l}\text { Calcário calcítico }+ \\
\text { bicarbonato de sódio }\end{array}$ & & \\
\hline Número de animais & 14 & 14 & 14 & & \\
\hline Idade inicial, dias & 88,5 & 87 & 88 & & \\
\hline Idade final, dias & 144,5 & 143 & 144 & & \\
\hline Peso inicial, kg & 20,72 & 21,89 & 21,14 & & \\
\hline Peso final, kg & 37,07 & 38,28 & 37,32 & 0,16 & NS \\
\hline Ganho médio diário, kg & 0,291 & 0,292 & 0,288 & 0,006 & NS \\
\hline \multicolumn{6}{|l|}{ Consumo de matéria seca } \\
\hline $\mathrm{kg} / \mathrm{dia}$ & 0,956 & 1,015 & 1,013 & 0,001 & NS \\
\hline g/kg $\left(\right.$ peso $\left.^{0,75}\right)$ & 76,52 & 79,01 & 80,27 & 1,17 & NS \\
\hline$\%$ peso & 3,29 & 3,37 & 3,44 & 0,04 & NS \\
\hline Conversão alimentar, $\mathrm{kg}$ MS/kg ganho ${ }^{4}$ & 3,42 & 3,50 & 3,53 & 0,07 & NS \\
\hline
\end{tabular}

${ }^{1}$ Erro-padrão da média.

2 Probabilidade de efeito dos agentes tamponantes. 
Embora o calcário calcítico seja eficiente em agregar íons $\mathrm{H}^{+}$livres, pela dissociação do cálcio e $\mathrm{CO}_{3}$, alguns destes $\mathrm{CO}_{3}$ são convertidos a $\mathrm{HCO}_{3}$, consumindo $\mathrm{H}^{+}$ nesse processo, o que reduz a acidez. Entretanto, o calcário calcítico é considerado ineficiente como tamponante ruminal, por sua baixa solubilidade no rúmen em $\mathrm{pH}$ acima de 5,5, o que impossibilita esse processo (Erdman, 1988). Desse modo, o calcário calcítico tipo filler, por ser mais finamente moído, pode ter maior solubilidade no rúmen e ser efetivo em manter o $\mathrm{pH}$ ruminal próximo da neutralidade, melhorando o desempenho animal. Todavia, neste estudo, não foi verificada diferença significativa entre as granulometrias dos calcários. Possivelmente, mesmo com menor granulometria, o tempo de retenção do calcário calcítico filler no ambiente ruminal foi insuficiente para que os efeitos fossem significativos, uma vez que o menor tamanho de partícula pode representar maior taxa de passagem e menor período de ação. Entretanto, Nussio et al. (1991) avaliaram o efeito da adição de 1 e $2 \%$ de calcário calcítico filler e de $1 \%$ de calcário calcítico filler com $0,5 \%$ de $\mathrm{NaHCO}_{3}$ em dietas contendo bagaço de cana-de-açúcar tratado com pressão e vapor sobre o desempenho de bovinos confinados e verificaram que a adição de $2 \%$ desse agente tamponante aumentou o ganho de peso dos animais. No entanto, esses autores não observaram efeito da associação calcário calcítico filler e $0,5 \%$ de $\mathrm{NaHCO}_{3}$.

Para avaliar a inclusão de doses crescentes de bicarbonato de sódio sobre o $\mathrm{pH}$ ruminal e a digestibilidade da celulose, Santra et al. (2003) reportaram que a inclusão de $1,5 \%$ desse agente tamponante promoveu as melhores respostas. Neste estudo, a adição de $1 \%$ de bicarbonato de sódio pode ter sido insuficiente para causar os efeitos desejados e influenciar na ação da monensina. No entanto, Rumpler et al. (1986) relataram que altos níveis de suplementação com $\mathrm{Na}^{+}$ou $\mathrm{K}^{+}$podem modificar os efeitos da monensina sobre a produção ruminal de metano por aumentar o gradiente de concentração desses íons, facilitando o transporte pelos ionóforos para dentro da membrana dos microrganismos. Entretanto, não foram verificadas interações entre a adição de monensina e bicarbonato de sódio no desempenho dos animais. Possivelmente, a adição de $1 \%$ de bicarbonato de sódio não foi suficiente para aumentar a concentração de $\mathrm{Na}^{+}$ para que ocorressem mudanças na ação do ionóforo. Esses resultados corroboram os obtidos por Lofgreen (1976), que não observou interações entre a adição de monensina e bicarbonato nas rações, mas notou aumento de $7 \%$ no ganho médio diário e de $8 \%$ na conversão alimentar de bovinos alimentados com rações contendo $90 \%$ de concentrado quando adicionou bicarbonato à ração. A adição de monensina não influenciou o ganho médio diário, mas melhorou em 9,1\% a conversão alimentar. Quando ambos, monensina e bicarbonato de sódio, foram adicionados à ração, não houve alteração nas variáveis estudadas.

Os parâmetros de carcaça avaliados não foram alterados pela adição dos tamponantes e da monensina sódica (Tabelas 4 e 5). Segundo Oliveira (2004), a utilização de ionóforos pode influenciar as características da carcaça por promover mudanças no perfil de ácidos graxos produzidos na fermentação ruminal. A redução na relação acetato:propionato pode reduzir a espessura de gordura, pois o acetato é o principal precursor de ácidos graxos no metabolismo animal.

Os valores obtidos para rendimentos de carcaça quente e de carcaça fria estão de acordo com os verificados por Queiroz et al. (2008), que obtiveram valores médios de 50,6 e 49,5\%, respectivamente, para cordeiros da raça Santa Inês alimentados com ração contendo alta proporção de concentrado. Valores semelhantes também foram obtidos por Urano et al. (2006), que avaliaram cordeiros Santa Inês

Tabela 4 - Parâmetros da carcaça de cordeiros alimentados com dietas contendo alta proporção de concentrado em associação à monensina sódica

\begin{tabular}{|c|c|c|c|c|}
\hline \multirow[b]{2}{*}{ Item } & \multicolumn{2}{|c|}{ Dieta } & \multirow[b]{2}{*}{$\mathrm{EPM}^{1}$} & \multirow[b]{2}{*}{$\mathrm{P}^{2}$} \\
\hline & Com monensina & Sem monensina & & \\
\hline Peso de abate, kg & 41,0 & 40,8 & 0,16 & NS \\
\hline Idade de abate, dias & 155,6 & 159,3 & 3,42 & NS \\
\hline Peso da carcaça quente, kg & 20,6 & 20,6 & 0,12 & NS \\
\hline Peso da carcaça fria, kg & 20,1 & 20,1 & 0,12 & NS \\
\hline Rendimento de carcaça quente, \% & 50,3 & 50,3 & 0,18 & NS \\
\hline Rendimento de carcaça fria, \% & 49,1 & 49,2 & 0,19 & NS \\
\hline Área de olho-de-lombo, $\mathrm{cm}^{2}$ & 14,1 & 13,7 & 0,24 & NS \\
\hline Espessura de gordura, mm & 1,8 & 1,9 & 0,09 & NS \\
\hline Perda por resfriamento, \% & 2,5 & 2,3 & 0,15 & NS \\
\hline
\end{tabular}

${ }^{1}$ Erro-padrão da média.

2 Probabilidade de efeito da adição de monensina sódica. 
Tabela 5 - Parâmetros da carcaça de cordeiros alimentados com dietas contendo alta proporção de concentrado em associação a agentes tamponantes

\begin{tabular}{|c|c|c|c|c|c|}
\hline \multirow[b]{2}{*}{ Item } & \multicolumn{3}{|c|}{ Agente tamponante } & \multirow[b]{2}{*}{$\mathrm{EPM}^{1}$} & \multirow[b]{2}{*}{$\mathrm{P}^{2}$} \\
\hline & $\begin{array}{l}\text { Calcário } \\
\text { calcítico }\end{array}$ & $\begin{array}{c}\text { Calcário calcítico } \\
\text { tipo filler }\end{array}$ & $\begin{array}{l}\text { Calcário calcítico + } \\
\text { bicarbonato de sódio }\end{array}$ & & \\
\hline Peso de abate, kg & 40,9 & 40,9 & 40,9 & 0,16 & NS \\
\hline Idade de abate, dias & 159 & 155 & 158,5 & 3,42 & NS \\
\hline Peso da carcaça quente, kg & 20,4 & 20,5 & 20,8 & 0,12 & NS \\
\hline Peso da carcaça fria, kg & 19,9 & 20,1 & 20,3 & 0,12 & NS \\
\hline Rendimento de carcaça quente, \% & 50,0 & 50,2 & 50,8 & 0,18 & NS \\
\hline Rendimento de carcaça fria, \% & 48,6 & 49,1 & 49,6 & 0,19 & NS \\
\hline Área de olho-de-lombo, $\mathrm{cm}^{2}$ & 14,0 & 14,0 & 13,7 & 0,24 & NS \\
\hline Espessura de gordura, mm & 1,7 & 1,8 & 1,9 & 0,09 & NS \\
\hline Perda por resfriamento, \% & 2,8 & 2,1 & 2,3 & 0,15 & NS \\
\hline
\end{tabular}

${ }^{1}$ Erro-padrão da média.

2 Probabilidade de efeito dos agentes tamponantes.

e obtiveram valor médio de 48,9 e 47,7\% para os rendimentos de carcaça quente e de carcaça fria, respectivamente.

A ausência de efeito da inclusão de monensina sódica sobre a área de olho-de-lombo e a espessura de gordura está de acordo com o reportado por Davis \& Erhart (1979) em pesquisa na qual utilizaram monensina sódica. Da mesma forma, Berger et al. (1981) e Oliveira (2004) avaliaram o uso de lasalocida e monensina sódica em bovinos e também não verificaram efeito sobre essas variáveis.

O valor médio de perdas por resfriamento obtido neste experimento está de acordo com os encontrados por Rocha et al. (2004) e Rodrigues et al. (2008), que encontraram valores médios de 2,0\% para para cordeiros da raça Santa Inês mantidos sob o mesmo sistema de produção.

\section{Conclusões}

A adição do calcário calcítico tipo filler e do bicarbonato de sódio em dietas contendo alta proporção de concentrado não melhora o desempenho dos cordeiros em comparação ao calcário calcítico comum. Entretanto, a adição de monensina sódica melhora a conversão alimentar. A utilização do calcário calcítico tipo filler ou do bicarbonato de sódio, com ou sem monensina sódica, não interfere nas características da carcaça de cordeiros confinados.

\section{Referências}

ASSOCIATION OF OFFICIAL ANALYTICAL CHEMISTS. Official methods of analysis. 15.ed. Arlington, 1990. v.1, $1117 p$.

BAGG, R. Mode of action of ionophores in lactating dairy cattle: usefulness of ionophores in lactating dairy cattle. In: SYMPOSIUM ON ONTARIO VETERINARY COLLEGE, 1997, Guelph. Proceedings... Guelph: University of Guelph, 1997. p.13-21.
BERGEN, W.G.; BATES, D.B. Ionophores: their effect on production efficiency and mode of action. Journal of Animal Science, v.58, p.1465-1483, 1984.

BERGER, L.L.; RICKE, S.C.; FAHEY JR, G.C. Comparison of two forms and two levels of lasalocid with monensina on feedlot cattle performance. Journal of Animal Science, v.53, p.1441- 1445, 1981.

DAVIS, G.V.; ERHART, A.B. Effect of monensin and urea in finishing steer rations. Journal of Animal Science, v.43, p.1-8, 1976.

ERDMAN, R.A. Dietary buffering requirements of the lactating dairy cow: a review. Journal of Dairy Science, v.71, n.12, p.3246-3266, 1988.

GOERING, H.K.; VAN SOEST, P.J. Forage fiber analysis (apparatus, reagents, procedures and some applications). Washington: Agricultural Reserch Service, 1970. 19p. (Agricultural Handbook, 379).

GOODRICH, R.D.; GARRETT, J.E.; GAST, D.R. et al. Influence of monensin on the performance of cattle. Journal of Animal Science, v.58, n.6, p.1484-1498, 1984.

LOFGREEN, G.P. A comparison of sodium bicarbonate with rumensin in a finishing ration. California Feeders Day Report, 1976, p.15-20.

MENDES, C.Q.; PEREIRA, E.M.; SUSIN, I. et al. Efeito do uso de monensina em dietas com alto concentrado sobre o desempenho de cordeiros confinados (compact disc). In: INTERNATIONAL SIMPOSIUM OF UNDERGRADUATED RESEARCH, 8., 2000, Piracicaba. Anais... Piracicaba: FEALQ, 2000. (CD-ROM).

NUSSIO, L.G.; BOIN, C.; SANTOS, P.A.P. et al. Efeito do calcário mais bicarbonato de sódio em dietas de bagaço de cana tratado com pressão de vapor no desempenho de bovinos confinados. In: REUNIÃO ANUAL DA SOCIEDADE BRASILEIRA DE ZOOTECNIA, 26., 1991, João Pessoa. Anais... João Pessoa: 1991. p.258.

OLIVEIRA, M.G. Desempenho de bovinos em confinamento suplementados com diferentes ionóforos. 2004. $55 \mathrm{f}$. Dissertação (Mestrado em Zootecnia) - Faculdade de Zootecnia e Engenharia de Alimentos, Universidade de São Paulo, Pirassununga.

QUEIROZ, M.A.A.; SUSIN, I.; PIRES, A.V. et al. Desempenho de cordeiros e estimativa da digestibilidade do amido de dietas com diferentes fontes protéicas. Pesquisa Agropecuária Brasileira, v.43, p.1193-1200, 2008.

ROCHA, M.H.M.; SUSIN, I.; PIRES, A.V. et al. Performance of Santa Ines lambs fed diets of variable crude protein levels. Scientia Agricola, v.61, n.2, p.141-145, 2004.

RODRIGUES, G.H.; SUSIN, I.; PIRES, A.V. et al. Substituição do milho por polpa cítrica em rações com alta proporção de 
concentrado para cordeiros confinados. Ciência Rural, v.38, n.3, p.789-794, 2008.

RUMPLER, W.V.; JOHNSON, D.E.; BATES, D.B. The effect of high dietary cation concentration on methanogenesis by steers fed diets with and without ionophores. Journal of Animal Science, v.62, p.1737, 1986.

RUSSELL, J.B.; STROBEL, H.J. Effect of ionophores on ruminal fermentation. Applied and Environmental Microbiology, v.55, n.1, p.811-820, 1989.

SANTRA, A.; CHATURVEDI, O.H.; TRIPATHI, R. et al. Effect of dietary sodium bicarbonate supplementation on fermentation characteristics and ciliate protozoal population in rumen of lambs. Small Ruminant Research, v.47, p.203212, 2003.

SUSIN, I. Potencial produtivo de ovinos Santa Inês confinados e alimentados com rações de alta proporção de concentrado.
2003. 105f. Tese (Livre Docência) - Escola Superior de Agricultura "Luiz de Queiroz", Universidade São Paulo, Piracicaba.

SUSIN, I.; MENDES, C.Q. Confinamento de cordeiros: uma visão crítica. In: SIMPÓSIO DE CAPRINOS E OVINOS DA EVUFMG., 2., 2007, Belo Horizonte. Anais... Belo Horizonte: Universidade Federal de Minas Gerais, 2007. 276p.

SCHELLING, G.T. Monensin mode of action in the rumen. Journal of Animal Science, v.58, p.1518, 1984.

URANO, F.S.; PIRES, A.V.; SUSIN, I. et al. Desempenho e características de carcaça de cordeiros confinados alimentados com grão de soja. Pesquisa Agropecuária Brasileira, v.41, n.10, p.1525-1530, 2006.

VAN SOEST, P.J.; ROBERTSON, J.B.; LEWIS, B.A. Methods for dietary fiber, neutral detergent fiber, and nonstarch polysacarides in relation to animal nutrition. Journal of Dairy Science, v.74, p.3583-3597, 1991. 